\title{
Daily physical activity and blood lactate indices of aerobic fitness in children
}

\author{
J. R. Welsman PhD and N. Armstrong PhD FPEA FIBiol \\ PEA Research Centre, School of Education, University of Exeter, Exeter, UK
}

This study examined the relationship between daily physical activity and aerobic fitness in 11-16-year-olds. Habitual physical activity was assessed in 28 boys (mean(s.d.) age 13.6(1.3) years) and 45 girls (mean(s.d) age 13.7(1.3) years) from minute-by-minute heart rate monitoring during 3 school days. Aerobic fitness was assessed by determining the percentage peak $\dot{V}_{2}$ at blood lactate reference values of 2.5 and $4.0 \mathrm{mmol}^{-1}$ during incremental treadmill running. The $4.0 \mathrm{mmoll}^{-1}$ level occurred at a mean(s.d.) value of 89(7)\% peak $\dot{V}_{\mathrm{O}_{2}}$ in both boys and girls and mean(s.d.) values at the $2.5 \mathrm{mmoll}^{-1}$ level were 82(9)\% peak $\dot{V}_{\mathrm{O}_{2}}$ in girls. Mean(s.d.) percentage time with heart rates at or above 140 beats $\min ^{-1}$ was $6(3) \%$ in boys and $5(3) \%$ in girls. Corresponding values for percentage time at or above 160 beats $\min ^{-1}$ were $3(2)$ for boys and 2(1) for girls. The number of 10 - and 20 -min periods of activity with the heart rate sustained above the 140 and 160 beats min $^{-1}$ thresholds were also totalled over the 3 days. No significant relationships were identified between percentage peak $\dot{V}_{2}$ at the 2.5 or $4.0 \mathrm{mmol}^{-1}$ blood lactate reference levels and either percentage time or number of 10 - or 20 -min periods above 140 or 160 beats $\min ^{-1}(P>$ 0.05). These results support the hypothesis that daily physical activity levels in 11-16-year-old children do not stress aerobic metabolism sufficiently to influence aerobic fitness.

Keywords: Blood lactate, physical activity, children

The question of whether or not children are sufficiently active on a day-to-day basis to promote aerobic fitness remains extremely difficult to answer, the major hindrance being the lack of objective methods for quantifying children's daily physical activity.

Recent studies from our laboratory exploiting the use of heart rate telemetry to gauge children's physical activity from continuous heart rate monitoring have reported disturbingly low levels of physical activity in 10-16-year-old subjects ${ }^{1,2}$. On the basis of current opinion these levels would be considered insufficient to benefit the cardiopulmonary system.

Address for correspondence: Dr J. R. Welsman, PEA Research Centre, School of Education, University of Exeter, Heavitree Road, Exeter, EX1 2LU, UK

(C) 1992 Butterworth-Heinemann Ltd 0306-3674/92/040228-05
We have subsequently demonstrated that physical activity levels and peak $\dot{V}_{\mathrm{O}_{2}}$ are unrelated in children of this age ${ }^{3}$. This conclusion was based upon our failure to identify relationships between treadmill or cycle ergometer determined peak $\dot{V}_{2}$ and various heart rate indices of physical activity. These included the percentage of total time monitored spent with heart rates above thresholds of 140 and 160 beats $\min ^{-1}$, and the frequency of 5-, 10- or 20-min periods with the heart rate sustained above these two thresholds. The findings were derived from a sample of 196 11-16-year-old children monitored for 3 school days.

Also using heart rate telemetry, but in contrast to our work, Atomi et al. ${ }^{4}$ found that peak $\dot{V}_{\mathrm{O}_{2}}$ was significantly correlated with total time spent with heart rate greater than 160 beats $\min ^{-1}$ in 11 10-year-old boys. This led them to conclude that the volume of daily physical activity at intensities greater than $60 \% \quad \dot{V}_{\mathrm{O}_{2} \max }$ might increase aerobic power.

In the light of these contrasting findings there is clearly a need to investigate further the fitness-activity relationship in children. Although Armstrong et al. ${ }^{3}$ failed to demonstrate a correlation between peak $\dot{V} \mathrm{O}_{2}$ and habitual physical activity, this does not exclude the possibility of a relationship between aerobic fitness and daily physical activity, Peak $\dot{V}_{\mathrm{O}_{2}}$ as a measure may lack sufficient sensitivity in children to detect variations in aerobic fitness as a result of different levels of daily physical activity. Furthermore, any relationships which exist may be obscured by the strong genetic component to peak $\dot{V}_{\mathrm{O}_{2}}$ (Reference 5) and the influences of normal growth and maturation ${ }^{6}$.

Aerobic exercise training in adult subjects typically induces improvements in submaximal blood lactate indices which are greater in magnitude than improvements in peak $\mathrm{VO}_{2}$ (References 7,8 ). This occurs because there is much greater scope for increasing the oxidative capacity of muscle than there is for enhancing the central mechanisms which limit peak $\dot{V} \mathrm{O}_{2}$ such as maximal cardiac output ${ }^{9}$. Consequently, submaximal measures of blood lactate are now widely used and accepted as valid and sensitive indices of aerobic fitness ${ }^{10}$.

The aim of the present study was to examine the relationship between children's submaximal aerobic fitness, as reflected by the percentage peak $\dot{V}_{\mathrm{O}_{2}}$ at 
blood lactate reference values, and their daily physical activity levels, in order to examine further whether fitness and activity are related in 11-16-yearolds.

\section{Subjects and methods}

In all, 73 untrained students aged 11-16 years participated in the study. Of these, 18 were randomly selected from the class lists of a local comprehensive school and all of those selected consented to participate. The remainder were selected randomly from those who volunteered to take part in the Coronary Prevention in Children Project ${ }^{11}$. Written informed consent was obtained from both the subjects and their parents. Mean(s.d.) age and physical characteristics of the sample are displayed in Table 1.

\section{Assessment of daily physical activity}

Physical activity was not measured directly, but the relative stress placed upon the cardiopulmonary system as a result of physical activity was recorded by monitoring the children's minute-by-minute heart rate for continuous periods. Heart rate data were collected for at least $10 \mathrm{~h}$ during 3 normal school days within the same week. This was achieved using a self-contained, computerized telemetry system (Sport Tester 3000, Cranlea, Birmingham, UK) which comprises a transmitter attached to the chest via a belt or electrodes and a microcomputer worn as a watch on the wrist. Heart rate data were retrieved and analysed through interfacing the watches with a microcomputer. Heart rate monitoring took place throughout the school year but in our experience activity levels do not differ significantly between summer and winter terms ${ }^{12}$.

The mean percentage times spent with the heart rate at or above thresholds of 140 and 160 beats min $^{-1}$ were calculated for each child over the 3-day monitoring period. In addition, the number of 10 and 20-min periods during which the heart rate was continuously sustained at or above the two threshold values during the 3 days were totalled for each child. This form of analysis, in contrast to calculation of percentage of time, is less responsive to transient elevations in heart rate due to other factors, such as emotion.

The choice of these thresholds was based upon current opinion which suggests that a weekly minimum of three $20-\mathrm{min}$ periods of sustained

Table 1. Physical characteristics and mean peak cardiopulmonary responses of subjects

\begin{tabular}{lcc}
\hline Physical characteristic & $\begin{array}{c}\text { Boys }(n=28) \\
\text { Mean }(s . d .)\end{array}$ & $\begin{array}{c}\text { Cirls }(n=45) \\
\text { Mean }(s . d .)\end{array}$ \\
\hline Age (years) & $13.6(1.3)$ & $13.7(1.3)$ \\
Height $(\mathrm{m})$ & $1.60(0.11)$ & $1.58(0.10)$ \\
Mass $(\mathrm{kg})$ & $48.7(10.5)$ & $48.7(8.5)$ \\
Peak $\mathrm{VO}_{2}\left(\mathrm{~m} \mathrm{~min}^{-1}\right)$ & $2.40(0.59)$ & $1.90(0.38)$ \\
Peak $\mathrm{VO}_{2}\left(\mathrm{ml} \mathrm{kg}^{-1} \mathrm{~min}^{-1}\right)$ & $49(5)$ & $39(5)$ \\
Peak heart rate (beats $\left.\mathrm{min}^{-1}\right)$ & $203(8)$ & $202(8)$ \\
\hline
\end{tabular}

activity with the heart rate raised to at least $80 \%$ of peak rate is necessary for the improvement of cardiopulmonary fitness in children ${ }^{13}$. This equates to a heart rate of 160 beats $\mathrm{min}^{-1}$ in these subjects. The same volume of activity at an intensity of $70 \%$ peak heart rate $\left(140\right.$ beats $\left.\mathrm{min}^{-1}\right)$ is the recommended minimum level for the promotion of health and the maintenance of current levels of cardiopulmonary fitness ${ }^{14}$. To put the heart rate thresholds into perspective, it is worth noting that brisk walking at $6 \mathrm{~km} \mathrm{~h}^{-1}$ and jogging at $8 \mathrm{~km} \mathrm{~h}^{-1}$ elicit steady-state heart rates averaging 146 and 164 beats $\min ^{-1}$ respectively, with children of this age ${ }^{3}$.

\section{Measurement of aerobic fitness}

With adult subjects it has become customary to assess submaximal aerobic fitness through the measurement of $\dot{V}_{\mathrm{O}_{2}}$ at a fixed blood lactate reference value of $4.0 \mathrm{mmoll}^{-1}$ (Reference 10). The choice of this value was based upon data which showed that this was, on average, the highest level of blood lactate which could be sustained without a progressive increase during extended bouts of submaximal exercise, i.e. it represented a maximal lactate steady state ${ }^{15,16}$. As a result it was hypothesized that this would be an optimal training intensity. In fact, interindividual variation in maximal lactate steady state is considerable $e^{17,18}$ and the actual lactate level obtained at the steady state is highly dependent upon the specific lactate methodology employed ${ }^{19}$. Nevertheless, performance at the 4-mmoll ${ }^{-1}$ level is highly related to endurance performance and sensitive to improvements in aerobic fitness with training ${ }^{7,20}$.

Although the $4.0-\mathrm{mmoll}^{-1}$ level has been used in the assessment of teenage athletes ${ }^{21,22}$, recent research from our laboratory has suggested that extrapolation of the $4.0-\mathrm{mmoll}^{-1}$ level for use with children and adolescents may be inappropriate as a result of their generally lower blood lactate responses to exercise ${ }^{23}$. Furthermore, we have demonstrated in 13-14-year-old subjects that the maximal lactate steady state occurs closer to $2.5 \mathrm{mmoll}^{-1}$ (Reference 24). Therefore, in the present study we have included the percentage peak $\dot{V}_{2}$ at fixed blood lactate reference levels of both $2.5 \mathrm{mmoll}^{-1}$ and $4.0 \mathrm{mmoll}^{-1}$ as the criteria of submaximal aerobic fitness.

Peak $\mathrm{V}_{2}$ was determined during an incremental running test to voluntary exhaustion. All children completed a standardized protocol which consisted of a 3-min warm-up at $8 \mathrm{~km} \mathrm{~h}^{-1}$ followed by a series of 3-min exercise bouts each separated by a pause of $1 \mathrm{~min}$. The first two stages were run at 8 and $10 \mathrm{~km} \mathrm{~h}^{-1}$. Thereafter speed was maintained and the treadmill progressively inclined by $2 \%$ increments. Inspired and expired gases were monitored continuously throughout the test using a computerized on-line gas analysis system comprising pneumotachograph (GM Instruments, Glasgow, UK), temperature probe $(\mathrm{H}$ and B Sensors, Bognor Regis, UK), a child's low-resistance respiratory valve (Hans Rudolph Valves, Cranlea, Birmingham, UK), mixing chamber (made in house to international specifications), infra-red carbon dioxide analyser (ADC, Hoddesdon, UK) and paramagnetic oxygen analyser 
(Servomex, Crowborough, UK). At flow rates of $2001 \mathrm{~min}^{-1}$ the resistance across the system was $0.039 \mathrm{mH}_{2} \mathrm{O}$ on the inspiratory and $0.041 \mathrm{mH}_{2} \mathrm{O}$ on the expiratory side. The system was calibrated before each test with gases of known concentration and the pneumotachograph checked against a 3-1 calibration syringe at a range of flow rates. Heart rate was monitored throughout using an electrocardiograph (Rigel, Morden, UK). In the absence of a plateau in $\dot{V} \mathrm{O}_{2}$, the highest value of oxygen uptake achieved was accepted as peak $\dot{V}_{2}$ provided the heart rate had reached age-predicted maximum or had levelled off before the final exercise intensity, and the respiratory exchange ratio was greater than 1.00 .

Blood samples were collected from a fingerprick into heparinized capillary tubes during the pause between treadmill stages. Without further treatment $25-\mu l$ samples were assayed immediately for lactate concentration using a YSI 23L whole blood lactate analyser (Yellow Spring Instruments, Yellow Springs, USA). From computer-generated graphs of percentage peak $\dot{V O}_{2}$ versus blood lactate concentration values of percentage peak $\dot{V}_{\mathrm{O}_{2}}$ at the $2.5-$ and 4.0- $\mathrm{mmoll}^{-1}$ reference levels were interpolated.

\section{Results}

Mean(s.d.) values for peak cardiopulmonary responses obtained with these subjects are displayed in Table 1.

The $2.5 \mathrm{mmoll}^{-1}$ blood lactate reference level occurred at mean(s.d.) values of $82(9) \%$ peak $\dot{V O}_{2}$ in boys and $78(12) \%$ in girls. The mean(s.d.) value at the $4.0 \mathrm{mmoll}^{-1}$ reference level was $89(7) \%$ peak $\dot{V}_{2}$ in both boys and girls.

Analysis of the 3-day heart rate data revealed that the mean(s.d.) percentage time spent with the heart rate at or above 140 beats $\min ^{-1}$ was $6(3) \%$ for boys and $5(3) \%$ for girls. Corresponding values at or above 160 beats $\min ^{-1}$ were $3(2) \%$ for boys and $2(1) \%$ for girls. At both thresholds, the values for boys were significantly higher than those for girls $(P<0.05)$. In Table 2 the percentage of children who achieved sustained periods of activity at the two thresholds is displayed. Correlation coefficients between all heart rate indicators of physical activity and percentage peak $\dot{V} \mathrm{O}_{2}$ at 2.5 and $4.0 \mathrm{mmol}^{-1}$ were not significant $(P>0.05)$ for either boys or girls.

\section{Discussion}

If performance at blood lactate reference values is to be expressed in terms of percentage peak $\dot{V}_{2}$, then it is important that the criteria described in the Subjects and methods section are strictly adhered to. The mean values obtained from this group of subjects (Table 1) are similar to previous reports involving children of comparable ages ${ }^{25,26}$.

It is difficult to compare the mean values of percentage peak $\dot{V}_{2}$ at the blood lactate reference values for this sample with those from other studies due to differences in methodology, in particular the lactate assay methodology. Many laboratories now assay lactate in whole blood, as in this study. However, it is important to recognize that such
Table 2. Percentage of subjects and number of sustained periods with heart rate at or above 140 or 160 beats min $^{-1}$ during 3 days of monitoring

\begin{tabular}{ccc}
\hline No. of periods & \% Boys $(n=28)$ & \% Girls $(n=45)$ \\
\hline $10-$ min periods $\geq 140$ & 37 & \\
0 & 25 & 27 \\
1 & 11 & 24 \\
2 & 29 & 9 \\
$\geq 3$ & & \\
$20-$ min periods $\geq 140$ & 71 & 80 \\
0 & 18 & 20 \\
1 & 7 & - \\
2 & 4 & - \\
$\geq 3$ & & 69 \\
$10-$ min periods $\geq 160$ & 57 & 27 \\
0 & 25 & 2 \\
1 & 4 & 2 \\
2 & 14 & 89 \\
23 & & 11 \\
$0-$ min periods $\geq 160$ & 79 & - \\
1 & 11 & - \\
2 & 11 & - \\
\hline 3 & - & \\
\hline
\end{tabular}

values differ from those derived from other assay methodologies which utilize blood preparations such as lysed blood or plasma ${ }^{19}$. However, the results obtained from this small sample are consistent with our previously published data which involved much larger sample sizes ${ }^{27}$.

Similarly, the activity levels of this group of children reflect our previous results ${ }^{1,3}$ showing in terms of both percentage time and sustained 10 - and 20-min periods with heart rate raised above the two heart rate thresholds, that these children are on average remarkably sedentary. The non-significant correlations between percentage peak $\dot{V}_{\mathrm{O}_{2}}$ at the two fixed blood lactate reference values and the heart rate indicators of physical activity suggest that these levels of activity are not of the frequency, duration and intensity necessary to exert a training effect upon submaximal aerobic fitness as reflected by blood lactate indices.

To date, only one other study appears to have examined the relationship between blood lactate measures of submaximal aerobic fitness and objectively assessed habitual physical activity in children ${ }^{4}$. Using the lactate threshold (breakpoint in the lactate-oxygen uptake curve) as their index of submaximal aerobic fitness, these authors identified a significant but negative relationship between percentage peak $\dot{\mathrm{O}}_{2}$ at the lactate threshold and the time spent with the heart rate above various indices, including the heart rate corresponding to the lactate threshold, $60 \%$ peak $\dot{\mathrm{O}}_{2}$ and a 160 beats $\mathrm{min}^{-1}$ threshold. This relationship is in fact the opposite of that which might be expected and may result first from the errors inherent in the subjective identification of the lactate threshold rather than the more objective measurement of performance at a fixed blood lactate reference value, and second the restricted sample size $(n=11)$.

During incremental exercise, children demonstrate significantly lower blood lactate levels than those of adults $^{28,29}$, which has led authors to note that the 
performance of untrained children at fixed blood lactate reference values compares favourably with that of highly trained adults ${ }^{28,30}$. The present data indicate that this 'trained' appearance of children's responses does not result from high levels of daily physical activity.

The age or stage of biological development at which blood lactate responses to exercise become adult remains unresolved. Several authors have noted age and/or maturational increases in blood lactate responses to exercise at given exercise intensities ${ }^{31}$ and the hormonal adjustments accompanying sexual maturation have been strongly implicated in boys ${ }^{32,33}$. However, in what appears to be the most recent and extensive study of blood lactate responses to incremental exercise in 11-16year-old boys and girls, no significant alterations in blood lactate response patterns during incremental exercise were observed with either increasing chronological age or Tanner stage of maturity ${ }^{34}$. Child-adult differences were noted to persist after adolescence ${ }^{35}$. In the light of these equivocal findings, it might be valid to suggest that blood lactate indices of aerobic fitness are inappropriate tools to examine the fitness-activity relationship in children. Conversely, one may justify the use of blood lactate indices on the basis that they have been shown to reflect improvements in performance with training in children ${ }^{22}$. Therefore the results of this study, in which objective methodology has been used for the assessment of both aerobic fitness and daily physical activity, strengthen our previous conclusion, based on the relationship between laboratory determined peak $\dot{V}_{\mathrm{O}_{2}}$ and habitual physical activity ${ }^{3}$, that current laboratory indices of aerobic fitness are unrelated to daily physical activity in 11-16-year-old children.

\section{Acknowledgements}

The technical assistance of Jenny Frost is gratefully acknowledged. Dr Welsman is supported by the British Heart Foundation.

\section{References}

1 Armstrong N, Balding J, Gentle P, Kirby B. Patterns of physical activity among 11 - to 16-year-old British children. $\mathrm{Br}$ Med J 1990a; 301: 203-5.

2 Armstrong N, Bray S. Physical activity patterns defined by continuous heart rate monitoring. Arch Dis Child 1991; 66: 245-7.

3 Armstrong N, Balding J, Gentle J, Williams J, Kirby B. Peak oxygen uptake and physical activity in 11- to 16-year-olds. Pediatr Exerc Sci 1990b; 2: 349-58.

4 Atomi Y, Iwaoka K, Hatta H, Miyashita M, Yamamoto Y. Daily physical activity levels in pre-adolescent boys related to $\dot{V}_{\mathrm{O}_{2} \max }$ and lactate threshold. Eur J Appl Physiol 1986; 55: 156-61.

5 Bouchard C, Lortie G. Heredity and endurance performance. Sports Med 1984; 1: 38-64.

6 Cunningham DA, Paterson DH, Blimkie CJR. The development of the cardiorespiratory system with growth and physical activity. In: Boileau RA, ed. Advances in Pediatric Sport Sciences, Vol. 1, Biological Issues, Champaign, Illinois, USA: Human Kinetics, 1984: 85-116.

7 Denis C, Dormois D, Lacour JR. Endurance training, $\dot{V}_{\mathrm{O}_{2} \max }$ and OBLA: a longitudinal study of two different age groups. Int J Sports Med 1984; 5: 167-73.

8 Gaesser GA, Poole DC. Lactate and ventilatory thresholds: disparity in time course of adaptations to training. I Appl Physiol 1986; 61: 999-1004.
9 Hagberg JM. Physiological implications of lactate threshold. Int J Sports Med 1984; 5 (Suppl): 106-9.

10 Hale T, Armstrong N, Hardman A, Jakeman P, Sharp C, Winter E. Position Statement on the Physiological Assessment of the Elite Competitor. Leeds, UK: British Association of Sports Sciences, 1988.

11 Armstrong N, Williams J, Balding J, Gentle P, Kirby B. The peak oxygen uptake of British children with reference to age, sex and sexual maturity. Eur J Appl Physiol 1991; 62: 369-75.

12 Armstrong N, Bray S. Primary schoolchildren's physical activity during Autumn and Summer. Bull Phys Educ 1990; 26: 23-6.

13 Massicotte DR, MacNab RBJ. Cardiorespiratory adaptations to training at specified intensities in children. Med Sci Sports 1974; 6: 242-6.

14 Simons-Morton BG, Parcel GS, O'Hara NM, Blair SN, Pate RR. Health-related physical fitness in childhood. Ann Rev Public Health 1988; 9: 403-25.

15 Mader A. The contribution of physiology to the science of coaching. In: Simri U, ed. The Art and Science of Coaching. Netanya, Israel: Wingate Institute Press, 1980: 10-19.

16 Heck H, Mader A, Hess G, Mucke S, Muller R, Hollman W. Justification of the $4 \mathrm{mmoll}^{-1}$ lactate threshold. Int J Sports Med 1985; 6: 117-30.

17 Stegmann $\mathrm{H}$, Kindermann $\mathrm{W}$. Comparison of prolonged exercise tests at the individual anaerobic threshold and the fixed anaerobic threshold of $4 \mathrm{mmoll}^{-1}$. Int J Sports Med 1982; 3: $105-10$

18 Haverty M, Kenny WL, Hodgson JL. Lactate and gas exchange responses to incremental and steady-state running. Br J Sports Med 1988; 2: 51-4.

19 Williams JR, Armstrong N, Kirby B. The influence of the site of sampling and the assay medium upon the measurement and interpretation of blood lactate responses to exercise. $J$ Sports Med 1992; 10: 95-107.

20 Jacobs I. Blood lactate: implications for training and sports performance. Sports Med 1986; 1: 10-25.

21 Sjodin B. The relationships among running economy, aerobic power, muscle power and onset of blood lactate accumulation in young boys (11-15 years). In: Komi PV, ed. Exercise and Sport Biology. Champaign, Illinois, USA: Human Kinetics, 1982: $57-60$.

22 Gaisl G, Weisspeiner G. Training prescriptions for 9- to 17-year-old figure skaters based on lactate assessment in the laboratory and on the ice. In: Rutenfranz J, Mocellin R, Klimt F, eds. Children and Exercise XII. Champaign, Illinois, USA: Human Kinetics, 1986: 59-66.

23 Williams J, Armstrong N, Kirby BJ. The $4 \mathrm{mM}$ blood lactate level as an index of exercise performance in 11-13-year-old children. J Sports Sci 1990; 8: 139-47.

24 Williams JR, Armstrong N. The maximal lactate steady state and its relationship to performance at the 2.5 and $4.0 \mathrm{mmoll}^{-1}$ blood lactate reference values in children. Pediatr Exerc Sci 1991; 3: 333-41.

25 Armstrong N, Balding J, Gentle P, Kirby B. Estimation of coronary risk factors in British schoolchildren: a preliminary report. Br J Sports Med 1990; 24: 61-6.

26 Palgi Y, Gutin B, Young J, Alejandro D. Physiologic and anthropometric factors underlying endurance performance in children. Int J Sports Med 1984; 5: 67-73.

27 Williams JR, Armstrong N, Kirby BJ. The blood lactate response to exercise in 11- to 16-year-old children with reference to cardiorespiratory variables, chronological age, sex and sexual maturity. J Sports Sci 1990; 8: 297-8.

28 Simon G, Berg A, Dickhuth HH, Simon-Alt A, Keul J. Determination of the anaerobic threshold depending on age and performance potential. Dtsch Z Sportsmed 1981;

32: 7-14.

29 Cumming GR, Hastman L, McCort J. Treadmill endurance times, blood lactate, and exercise blood pressures in normal children. In: Binkhorst RA, Kemper HCG, Saris WHM, eds. Children and Exercise XI. Champaign, Illinois, USA: Human Kinetics, 1985: 140-50.

30 Atomi $Y$, Iwaoka $\mathrm{K}$, Hatta $\mathrm{H}$, Miyashita $\mathrm{M}$, Yamamoto $\mathrm{Y}$. Relationship between lactate threshold during running and relative gastrocnemius area. Eur J Appl Physiol 1987; 55: 56-161.

31 Wirth A, Trager E, Scheele $\mathrm{K}$ et al. Cardiopulmonary adjustment and metabolic response to maximal and submaxi- 
mal physical exercise of boys and girls at different stages of maturity. Eur J Appl Physiol 1978; 39: 229-40.

32 Bar-Or O. The growth and development of children's physiologic and perceptional responses to exercise. In: Ilmarinen J, Valimaki I, eds. Children and Sport. Berlin, Germany: Springer, 1984: 3-17.

33 Fellman N, Bedu M, Spielvogel $\mathrm{H}$. et al. Anaerobic metabolism during pubertal development at high altitude. $J$ Appl Physiol 1988; 64: 1382-6.
34 Williams JR, Armstrong N. The influence of age and sexual maturation on children's blood lactate responses to exercise. Pediatr Exerc Sci 1991; 3: 111-20.

35 Williams JR. The blood lactate response to exercise in 11- to 16-year-old children with reference to cardiorespiratory variables, chronological age, sex, sexual maturity and habitual physical activity. Unpublished PhD thesis, University of Exeter, UK, 1990 .

\section{BASM Merchandise (October 1992)}

Ladies scarves

Sweatshirts

Tee shirts

Ties

Blazer badge
White with blue border and BASM logo - 27-inch square

Navy blue with fringe and BASM logo $54 \times 9$ inches (oblong)

Navy blue with hood: medium only $36-28$ inches

White without hood: medium 36-38 inches; large 40-42 inches; extra large 44 inches; very small (child size 4 )

Light blue: medium 36-38 inches; large 40-42 inches; extra large 44 inches

Navy blue: small 34-36 inches; medium 36-38 inches; extra large 44 inches; very small (child size 4 )

Single motif

Multi motif

Wire -4 inches high
$£ 5+£ 1 p \& p$

$£ 5+£ 1 p \& p$

$£ 11+£ 1 p \& p$

$£ 10+£ 1 p \& p$

$£ 6+£ 1 \mathrm{p} \& \mathrm{p}$

$£ 6+£ 1 p \& p$

$£ 6+£ 1 p \& p$

$£ 5+£ 1 \mathrm{p} \& \mathrm{p}$

New stock to order

Track/leisure suits Umbro, with small motif to order: ladies: $10,12,14,16$

Quotes

gents: $\mathrm{S}, \mathrm{M}, \mathrm{L}, \mathrm{XL}$

Sweaters Lambswool with small motif

Colours and chest size to order

$£ 26+£ 1 p \& p$

Dress shirts

White short sleeve, small motif

Collar size to order

$£ 16+£ 1 p \& p$

Sweatshirts

Small motif

Colours and chest size to order

$£ 13+£ 1 p \& p$

Polo shirts

Small motif

Colours and chest size to order

$£ 12+£ 1 p \& p$

Umbrellas

With motif to order

$£ 18+£ 2 p \& p$

For further details please contact: John H. Clegg JP LDS RCS Eng, National Sales Officer, Birch Lea, 67 Springfield Lane, Eccleston, St. Helens, Merseyside WA10 5HB, UK. (Tel: 0744 28198) 